\title{
Carbon C 11-osimertinib
}

National Cancer Institute

\section{Source}

National Cancer Institute. Carbon C11-osimertinib. NCI Thesaurus. Code C156742.

A radioconjug ate composed of osimertinib, a third-generation, orally available, irreversible, mutant-selective, epidermal growth factor receptor (EGFR) inhibitor, labeled with the positron-emitting isotope carbon C 11, with potential use in imaging via positron emission tomography (PET). Upon intravenous administration of carbon C 11 osimertinib, the osimertinib targets and binds to mutant forms of EGFR on tumor cells. Upon PET imaging, this radioligand may allow for the assessment of EGFR mutantexpressing tumor cells. This also allows assessment of osimetinib's pharmacokinetic profile and affinity of EGFR mutant-positive cancer cells and may identify patients who may respond well to osimertinib. 